\title{
Effect of Osmotic Stress and Nutrient Starvation on the Growth, Carotenoid and Lipid Accumulation in Dunaliella salina A9
}

\author{
Trung Vo, ${ }^{1, *}$, Truc Mai ${ }^{2}$, Hong Vu ${ }^{1}$, Dan Van ${ }^{1}$, Hien Dao ${ }^{1}$, Phong $\operatorname{Tran}^{1}$, Ngoc Nguyen ${ }^{1}$, \\ Phuc Nguyen ${ }^{1}$, Nguyen C. Nguyen ${ }^{3}$ \\ ${ }^{1}$ Department of Biochemistry and Toxicology, Nguyen Tat Thanh University, Viet Nam \\ ${ }^{2}$ Department of Plant and Environmental Sciences, New Mexico State University, New Mexico, USA \\ ${ }^{3}$ Department of Biotechnology, International University-VNU, Viet Nam \\ *Corresponding author: vohongtrung@ gmail.com
}

\begin{abstract}
Dunaliella salina A9 is unicellular green alga isolated from the saltern, Khanh Hoa province, Viet Nam. The effect of halostress and nutrient starvation was studied in this alga to estimate the growth, chlorophyll content and capacity of carotenoid and lipid accumulation. The results showed decrease in cell number and chlorophyll content as Dunaliella salina in response to a change from the optimal medium $1.5 \mathrm{M} \mathrm{NaCl}$ to hypo-osmotic medium $(0.5 \mathrm{M} \mathrm{NaCl})$ and hyper-osmotic medium $(3.5 \mathrm{M} \mathrm{NaCl})$. We also observed decrease in cell count in nutrient starvation after 9 days of culture in MD4 medium. Salinity stress has more severe effect on the growth of Dunaliella salina A9 with greater decrease in cell number compared to nutrient starvation. The stress induced increasing carotenoid and lipid accumulation in cells. However the carotenoid and lipid accumulation in hypo-osmotic stress and the nutrient starvation were higher than in hyper-osmotic stress. The results suggested negative relationship between the growth rate, chlorophyll content and carotenoid, and lipid accumulation of Dunaliella salina under stress conditions.
\end{abstract}

Keywords: Dunaliella, Dunaliella salina A9, carotenoid, lipid, sulfo-phospho-vanillin reagent

Cite This Article: Trung Vo, Truc Mai, Hong Vu, Dan Van, Hien Dao, Phong Tran, Ngoc Nguyen, Phuc Nguyen, and Nguyen C. Nguyen, "Effect of Osmotic Stress and Nutrient Starvation on the Growth, Carotenoid and Lipid Accumulation in Dunaliella salina A9." Research in Plant Sciences, vol. 5, no. 1 (2017): 1-8. doi: 10.12691/plant-5-1-1.

\section{Introduction}

Unicellular green algae of the genus Dunaliella is a halophillic eukaryote, ovoid form, flagellated and lack a rigid polysaccharide wall and thus have been found to be able to rapidly change their volume and shape in response to changes in the extracellular hypo-or hyper-osmotic pressure [2,29,33]. The osmotic response process of Dunaliella under salinity stress include the changes of cell volume, intracellular ions concentration, intracellular glycerol concentration, and the expression of some saltinduced genes [13].

The algal genus Dunaliella possess the unique ability to accumulate large amounts of $\beta$-carotene both in nature or adverse growth conditions such as high light intensity, high salt concentration, extreme temperatures or nutrient deficiency. $\beta$-carotene accumulation was concentrated in intra-chloroplastic lipoidal globules [4]. The green alga $D$. salina became one of the most important biological sources of $\beta$-carotene [17]. D. salina could accumulate $\beta$-carotene up to $50 \mathrm{mg} \cdot \mathrm{g}^{-1}$ of dry weight. Under the conditions of high light, high salinity, and nutrient deprivation, up to $10 \%$ of the dry weight in D. salina could be $\beta$-carotene $[4,11]$.

In Dunaliella salina, the contents of total lipids, unsaponifiables and fatty acid composition were basically depend on $\mathrm{NaCl}$ and nitrogen concentration in the culture. Increasing $\mathrm{NaCl}$ combined with decreasing $\mathrm{N}$ levels in the growth medium increased the total unsaturated fatty acids (TU) at the expense of total saturated fatty acids [15]. This study aimed to estimate ability of carotenoid and lipid accumulation under stress conditions such as hypo-hyper osmotic stress and nutrient starvation in Dunaliella salina A9 isolated from the saltern, Khanh Hoa province, Viet Nam.

\section{Materials and Methods}

\subsection{Dunaliella salina Strain and Medium}

The strain used in this study was D. salina A9 isolated from the saltern, Khanh Hoa province, Viet Nam. The alga was grown in $1.5 \mathrm{M}$ MD4 medium containing NPK $0.1 \mathrm{~g} / \mathrm{l}$, $\mathrm{MgSO}_{4} 1.86 \mathrm{~g} / \mathrm{l}$, EDTA $0.00876 \mathrm{~g} / \mathrm{l}, \mathrm{FeCl}_{3} \quad 0.00049 \mathrm{~g} / \mathrm{l}$, $\mathrm{MnCl}_{2} 0.00189 \mathrm{~g} / \mathrm{l}, \mathrm{NaHCO}_{3} 50 \mathrm{mM}, \mathrm{pH}=7.5$ [39], 
at $25^{\circ} \mathrm{C}$ under continuous light intensity of $50 \mu \mathrm{mol}$ photon $/ \mathrm{m}^{2} / \mathrm{s}$.

\subsection{Experiment Design}

The alga $D$. salina A9 was grown in $1.5 \mathrm{M} \mathrm{NaCl} \mathrm{MD4}$ medium to exponential phase (after 9 days) and then stressed with two salinities: hypo-hyper osmotic stress by transferring to $0.5 \mathrm{M}$ (hypo-osmotic stress) and $3.5 \mathrm{M}$ (hyper-osmotic stress) growth medium, and nutrient starvation. For hypo-osmotic stress, this algal culture centrifuged at $3000 \mathrm{rpm}$ for $5 \mathrm{~min}$, then pellets were transferred to $0.5 \mathrm{M}$ MD4 medium. For hyper-osmotic stress, $\mathrm{NaCl}$ added to $1.5 \mathrm{MD} 4$ medium to obtain $3.5 \mathrm{M}$ $\mathrm{NaCl}$ concentration. Chlorophyll content, carotenoid and lipid accumulation determined before and every three days after the stress. The experiments were triplicated.

\subsection{Growth Analysis}

$100 \mu \mathrm{l}$ algal suspension were stopped movement by Lugol solution (5\% iodine and $10 \%$ potassium iodide). Cell density was determined by direct counting every three days, using a light microscope with $0.1 \mathrm{~mm}$ deep counting chamber (Neubauer Haemocytometer). Cell number was determined by following formula: Number of cells $/ \mathrm{ml}=$ total cells counted $\times 10^{4} \times$ dilution factor .

\subsection{Total Carotene and Chlorophylls}

One milliliter aliquot of algal suspension was centrifuged at $5000 \mathrm{rpm}$ for $5 \mathrm{~min}$ and the pellet extracted with $3 \mathrm{ml}$ of ethanol:hexane 2:1 (v/v). Two milliliters of water and $4 \mathrm{ml}$ hexane were added and the mixture vigorously shaken and centrifuged again at $5000 \mathrm{rpm}$ for 5 $\min$. The hexane layer was separated and its absorbance at 450nm, $662 \mathrm{~nm}$ and $645 \mathrm{~nm}$. Total carotene: $\mathrm{A}_{450} \times 25.2$ equal the micrograms of carotene in sample $[32,36]$. Chl $a$ and Chl $b$ contents were estimated according to Lichtenthaler and Wellburn [20]:

$$
\begin{aligned}
& \text { Chla }(\mu \mathrm{g} / \mathrm{ml})=11.75(\mathrm{~A} 662)-2.35(\mathrm{A645}) \\
& \mathrm{Chlb}(\mu \mathrm{g} / \mathrm{ml})=18.61(\mathrm{A645})-3.96(\mathrm{A662}) \\
& \text { Total chlorophyll }=\mathrm{Chl} a+\mathrm{Chl} b
\end{aligned}
$$

Where: Chl $a$ is chlorophyll a, Chl $b$ is chlorophyll b

\subsection{Sulfo-phospho-vanillin Assay for Lipid Accumulation}

Phosphovanillin reagent was prepared by initially dissolving $0.06 \mathrm{~g}$ vanillin in $2 \mathrm{ml}$ absolute ethanol; $8 \mathrm{ml}$ deionized water and stirred continuously. Subsequently 50 $\mathrm{ml}$ of concentrated phosphoric acid was added to the mixture, and the resulting reagent was stored in the dark until use. To ensure high activity, fresh phospho-vanillin reagent was prepared shortly before every experiment run [26].

For SPV reaction of the algal culture for lipid quantification, One $\mathrm{mL}$ of algal suspension was centrifuged at $5000 \mathrm{rpm}$ for $5 \mathrm{~min}$ and the pellet was extracted with $2 \mathrm{~mL}$ of concentrated (98\%) sulfuric acid was added to the sample and was heated for $10 \mathrm{~min}$ at $100^{\circ} \mathrm{C}$, and was cooled for $5 \mathrm{~min}$ in ice bath. $5 \mathrm{~mL}$ of freshly prepared phospho-vanillin reagent was then added, and the sample was incubated for $15 \mathrm{~min}$ at $37^{\circ} \mathrm{C}$ incubator shaker at $200 \mathrm{rpm}$. Absorbance reading at 530 $\mathrm{nm}$ was taken in order to quantify the lipid within the sample [26].

\subsection{Data Analysis}

Data was processed in Excel 2013 and analyzed by oneway ANOVA using SPSS software version 20.0. All significant levels were set at $\mathrm{p}<0.05$.

\section{Results and Discussion}

\subsection{The Growth of Dunaliella salina A9}

Dunaliella salina A9 was grown in 1.5M MD4 medium with the growth rate of $0.29 \mathrm{cell} / \mathrm{ml} / \mathrm{day}$ in exponential phase (from day 0 to day 9). Cell density decreased markedly as salinity in the culture medium increased from $1.5 \mathrm{M}$ growth medium to $3.5 \mathrm{M}$ or decreased to $0.5 \mathrm{M}$. Compared to nutrient starvation condition, altered salinity affects cell density more severely. Cell survival recovered in $3.5 \mathrm{M} \mathrm{NaCl}$ stress from day 19 to day 21 (89 cells $/ \mathrm{ml}$ and 107 cells/ml, respectively), but recovery was not observed in hypo-osmotic salt stress. Dunaliella salina A9 cells adapted with the hyper-osmotic condition after 6 days of stress (Figure 1).

According to Al-Hasan et al. [1] there were some correlation among halostress-induced changes in the growth rate, pigmentation, chloroplast structure and lipid composition of $D$. salina. Dunaliella salina has an impressive capacity to grow in different salt concentrations. Upon hypo-saline shock conditions (cells were transferred from $9 \% \mathrm{NaCl}$ growth media to 3 or $6 \%$ $\mathrm{NaCl}$ growth media), cells transiently and rapidly (within minutes) increased in sizes and slowly over hours acquired their original size and volume. Upon hyper-saline shock by transferring from $9 \% \mathrm{NaCl}$ to 12 or $15 \% \mathrm{NaCl}$ growth media, cells transiently decreased in size (within minutes) and then slowly within hours regained the original size. Cell population grown in lower concentration of $\mathrm{NaCl}$ was smaller and more uniform in size than those grown in the condition with higher concentrations of $\mathrm{NaCl}$. This property reflects that $D$. salina has a potential to regulate the cell volume, thereby allowing the cells to tolerate large variations in the salt concentration of growth media [41].

Dunaliella, particular Dunaliella salina can accumulate a larger amount of carotene and lipid when they cultured under adverse conditions such as high light intensity, high salt concentration, extreme temperatures and nutrient deficiencies. Phadwal and Singh [30] was evaluated that under sulphate, nitrate and phosphate limitation Dunaliella decreased in the growth rate and chlorophyll content but, increased in the beta-carotene content. Dunaliella cell number decreased and increased in cell sizes after salinity stress. Cells transferred from green to yellow or orange in the color [38]. Upon the stress, Dunaliella salina A9 cells were changed in the structure, physiology and metabolism with the reduced growth and chlorophyll content, but the enhanced carotenoid and lipid biosynthesis. 


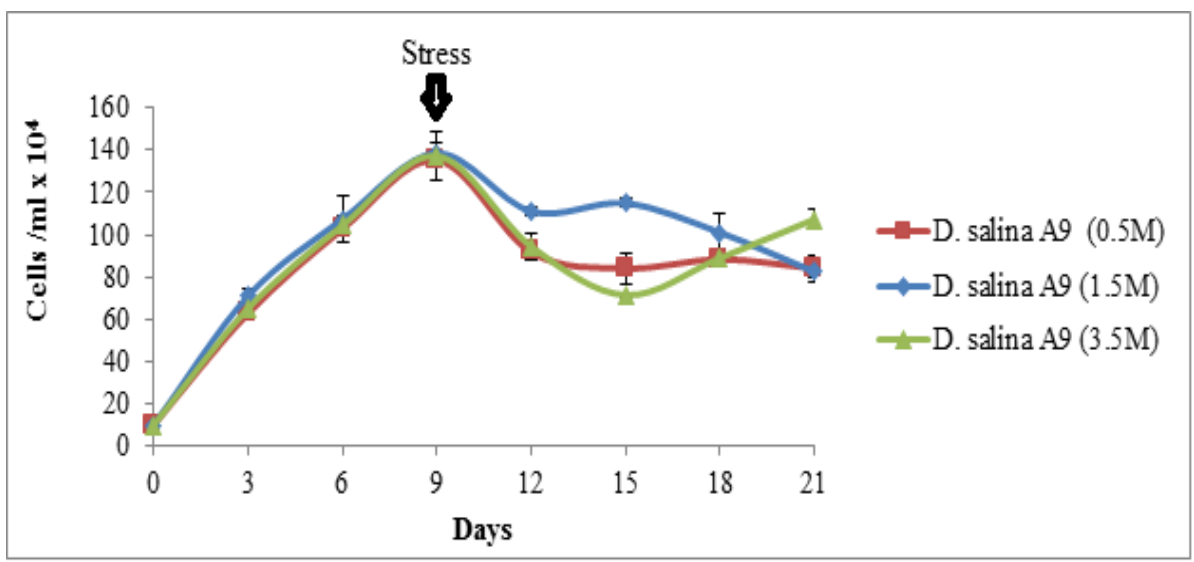

Figure 1. The growth curve of Dunaliella salina A9 under the different stress
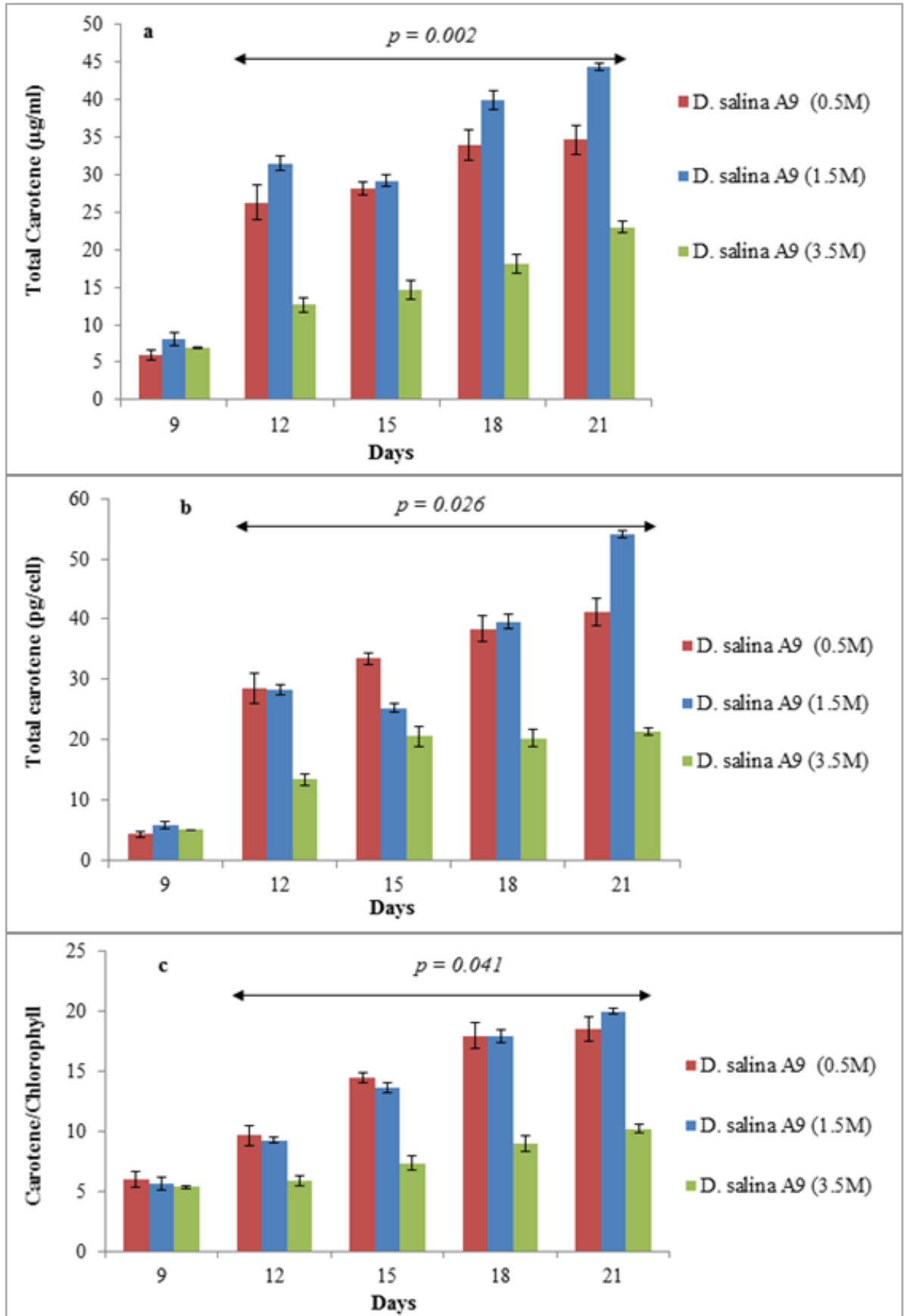

Figure 2. Carotenoid content of D. salina A9, carotenoid per volume (a), carotenoid per cell (b) and carotenoid to chlorophyll ratio (c) under the different stress 


\subsection{Carotenoid Content of Dunaliella salina A9}

Carotenoid content of $D$. salina A9 increased as the salt stress and the nutrient starvation. This increase in the hypo-osmotic stress and the nutrient starvation were more than in the hyper-osmotic stress. There were no significant differences in carotenoid content between the hypo-osmotic stress and the nutrient starvation, carotenoid per volume $(p=0.367)$, carotenoid per cell $(p=0.972)$ and carotenoid to chlorophyll ratio $(p=1.000)$ (Figure 2). Carotenoid content per cell was no significant difference in hypo-osmotic stress from day 15 ( $p=0.074$ ) (Figure $2 b$ ). The carotenoid to chlorophyll ratio in the hypo-osmotic stress and the nutrient was higher than in the hyperosmotic stress. There was significant difference in the carotenoid to chlorophyll ratio after 6 days stress under the hyper-osmotic stress $(p=0.028)$ (Figure 2c).

Changes in culture conditions, nutrients deficiency, physical modifies and regimen growth are developed as strategies in microalgae cultures to increase compounds of interest to different process $[9,21,28,34]$. In D. bardawil, increasing light intensity and light period or inhibiting growth by various stress conditions such as nutrient deficiency or high salt concentration caused a decrease in the content of chlorophyll per cell and an increase in the amount of $\beta$-carotene per cell and the $\beta$-carotene-to-chlorophyll ratio [4]. $\beta$-carotene accumulation of Dunaliella salina is enhanced up to $10 \%$ of the alga dry weight under several conditions: high irradiance, stress temperatures, high salt concentration and/or nutrient deficiency $[7,32]$.

When increasing salinity the Dunaliella salina cells became enriched with carotenoid globules that were concentrated at the cell periphery. The chloroplast was degenerated as halostress and the carotenoid globules increased in size. At higher salt concentrations the lamellae degenerated into smaller, less compact units dispersed in the cytoplasm. However, intact thylakoids were still recognized [1].

The adaptation of $D$. salina to salt stress can enhance rapidly the intracellular concentration of glycerol and glycine betaine, neutral lipid biosynthesis and carotenoid overaccumulation [33]. Fluctuations in medium osmolarity result in changes of plasma membrane lipid order, thus triggering activation of a protein kinase cascade and ultimately leading to conversion of starch into glycerol in the chloroplast [31]. In addition to the salt stress were responsible for changes in gene expression events through an as yet unidentifed transcription factor or factors followed by de novo protein biosynthesis. Known salt stress-induced gene products include transcripts and proteins involved in carbon and iron assimilation as well as carotenoid biosynthesis [14,16,33]. Our previous results documented that decreased in cell growth is accompanied by carotenoid biosynthesis and lipid content of Dunaliella salina after 9 days nutrient stress [22].

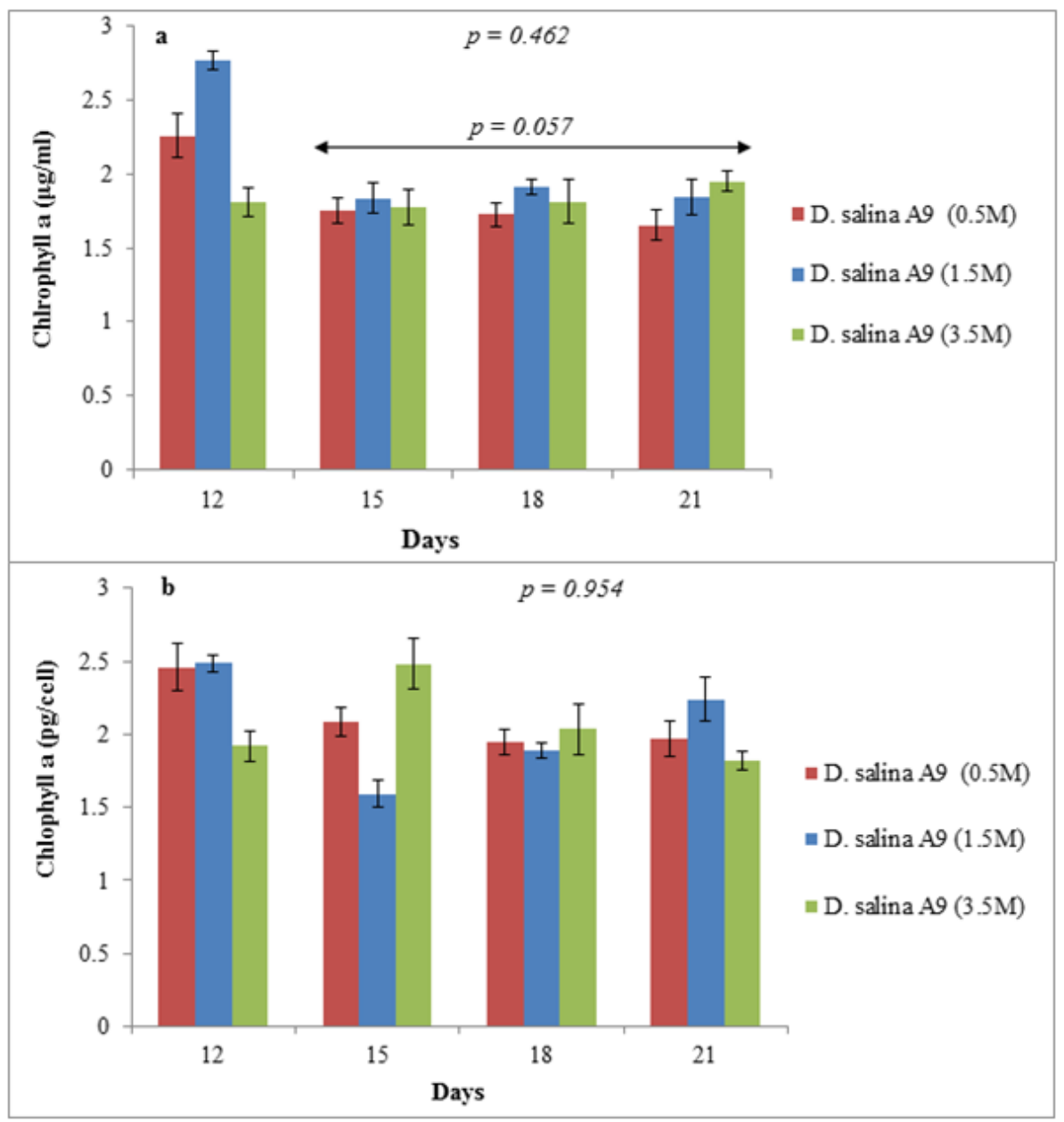

Figure 3. Chlorophyll a content, chlorophyll a per volume (a) and chlorophyll a per cell (b) under the different stress 


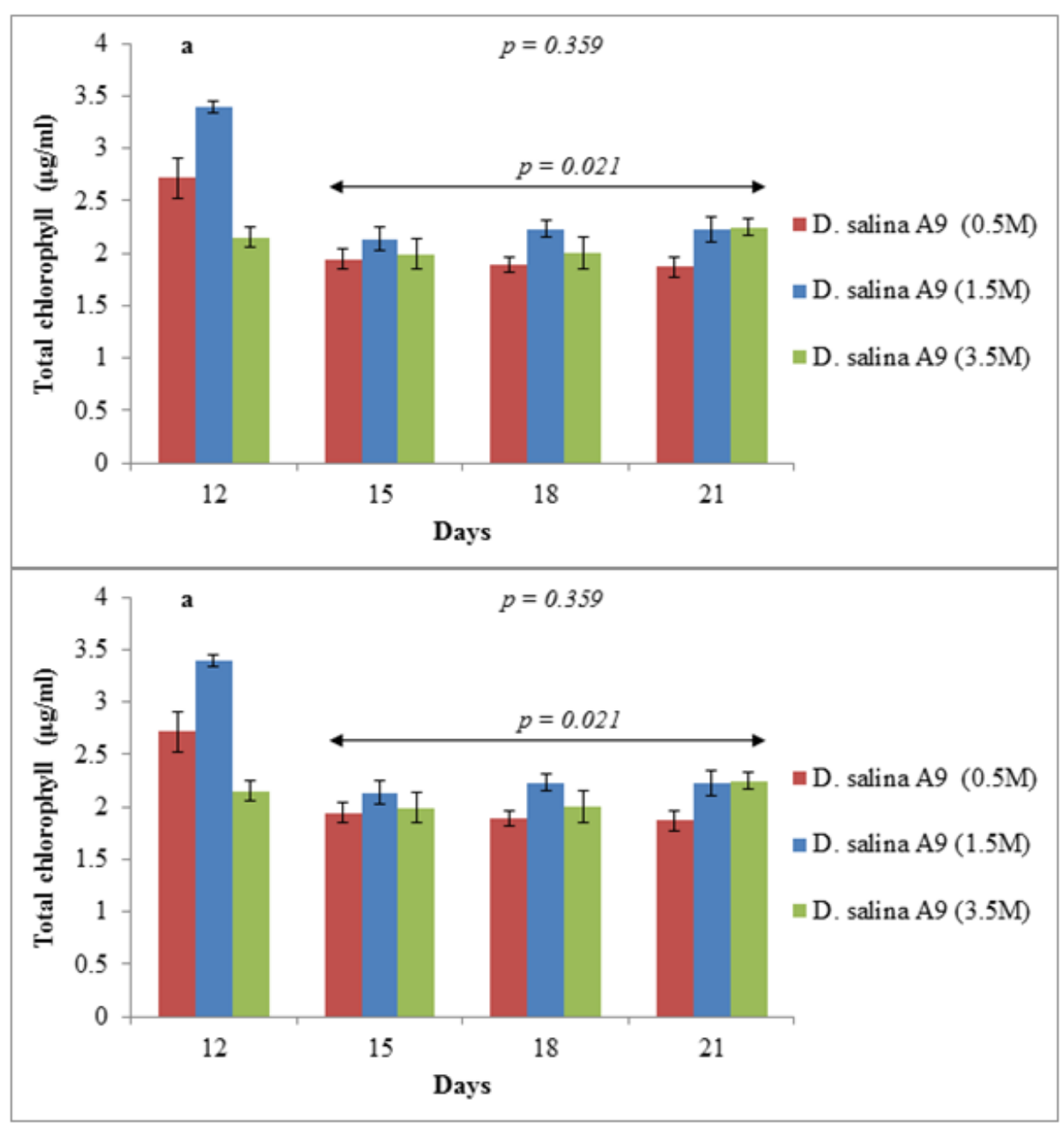

Figure 4. Total chlorophyll content, total chlorophyll per volume (a) and total chlorophyll per cell (b) under the different stress

\subsection{Chlorophyll Content of Dunaliella salina A9}

Chlorophyll a and total chlorophyll per volume of D. salina A9 decreased after 3 days stress and no significant difference after 6 days stress (Figure 3a, Figure 4a). Chlorophyll $a$ and total chlorophyll per cell decreased strongly under condition of the hypo-osmotic stress and nutrient starvation for 6 days after the stress. While chlorophyll content per cell was not change under the hyper-osmotic stress (Figure 3b, Figure 4b). The decrease in chlorophyll content of Dunaliella salina triggered decrease in growth (Figure 1) and induced increase in carotenoid biosynthesis (Figure 4), and lipid accumulation (Figure 5).

Nitrogen and phosphorous are important elements for life and acquired for optimal growth and production of biomass in microalgal culture. Chlorophyll is a nitrogen-rich compound and is easily accessible, it is utilized as an intracellular nitrogen pool to support further cell growth and biomass production as the nitrogen in the media becomes depleted [19]. In marine phytoplankton, nitrogen limitation affects photosynthesis by reducing the efficiency of energy collection due to loss of chlorophyll and increases in non-photochemically active carotenoid pigments. It also directly affects photochemical energy conversion because of a decrement in protein synthesis that appears to affect chloroplastic proteins (and thus the proteins of SI and PSII reaction centers) more strongly than cytoplasmic proteins [10]. No significant difference in chlorophyll content for 6 days after the stress (Figure 3, Figure 4) reflected adaption of Dunaliella salina A9 to the stress conditions with increasing the cell number (Figure 1).

The chlorophyll content of $D$. salina A9 decreased as nutrient starvation (Figure 4). Growth of cells depleted the nitrogen in the media, chlorophyll was degraded to reutilize the nitrogen for growth with chlorophyll $a$ and $b$ levels decreasing [9]. In Neochloris oleoabundus a rapid decrease in chlorophyll a was observed after 2 days of culture in low-nitrogen treatments. The chl a content started to decrease by day 4 in intermediate nitrogen treatment and did not decrease in higher nitrogen treatments [19].

Halostress injures the chloroplast and elevates the carotene to chlorophyll ratio, apparently to combat this injury [6]. This caused the reduced growth rates (Figure 1) and changes in biochemical compositions of Dunaliella salina cells such as chlorophyll (Figure 3, Figure 4), carotenoid content (Figure 2) and lipid accumulation (Figure 5).

\subsection{Lipid Accumulation of Dunaliella salina A9}

Figure 5 indicate the effect of the osmotic stress and nutrient starvation on lipid accumulation of D. salina A9. 
Lipid accumulation increased after the stress, while the hypo-osmotic stress and the nutrient starvation were higher lipid concentration than the hyper-osmotic stress (Figure 5). Lipid accumulation of $D$. salina A9 increased immediately and remained at about the same after the hypo-osmotic stress. While in the nutrient starvation lipid accumulation increased slowly and the highest after 9 days stress (Figure 5b).

Salinity is an intricate stress factor affecting net lipid productivity in microalgal cells [25]. Ben-Amotz et al. [8] documented the relationship between the chemical composition of eukaryotic algae and environmental conditions and species specific response with a general trend to protein decrease and carbohydrate increase on nitrogen starvation. Many algae accumulate lipids under nitrogen deficient conditions, and a few, such as Chlorella and contain $70 \%$ of the algal organic weight lipid [5].

Dunaliella species have been found to have unusually high contents of total lipids, carotenoids and polyunsaturated fatty acid (PUFA) such as 16:4 as well as 18:3 [6,24]. The patterns of constituent fatty acids of the total lipids varied according to the $\mathrm{NaCl}$ concentration. When the salinity was raised from 2.5 to $20 \%$ there was an increase in the proportion of the polyunsaturated fatty acid 18:3 [1]. Currently, lipid signal can be used as an additional marker for large detection of Dunaliella salina strains, with the support of morphology and salinity tolerance ability, lipid droplets can be seen in the inner part of the cells and increased after salinity stress [38].

Neochloris oleoabundans is a green microalga well known for the ability to increase its fatty acid (FA) content when it is cultured under nitrogen depletion. When nitrogen was consumed, cell division stopped, even though biomass accumulation continued for several days. The new biomass was composed mostly of lipids and storage oils [19]. The results demonstrated that there were positive relationship between carotenoid content and lipid accumulation of $D$. salina A9 after the stress.

Azachi et al. [3] found that the gene Kcs encoding for $\beta$-ketoacyl-CoA synthase is upregulated in salt stress, resulting in shifting of $\mathrm{C} 16$ fatty acids to $\mathrm{C} 18$ fatty acids component in microsomes and plasma membrane, and probably an increase in substrate for desaturation. The cells grown in $3.5 \mathrm{M} \mathrm{NaCl}$ contained a considerably higher ratio of $\mathrm{C} 18$ (mostly unsaturated) to $\mathrm{C} 16$ (mostly saturated) fatty acids compared with cells grown in $0.5 \mathrm{M}$ salt. The salt-inducible Kcs may play a role in adapting intracellular membrane compartments to function in the high internal glycerol concentrations balancing the external osmotic pressure.

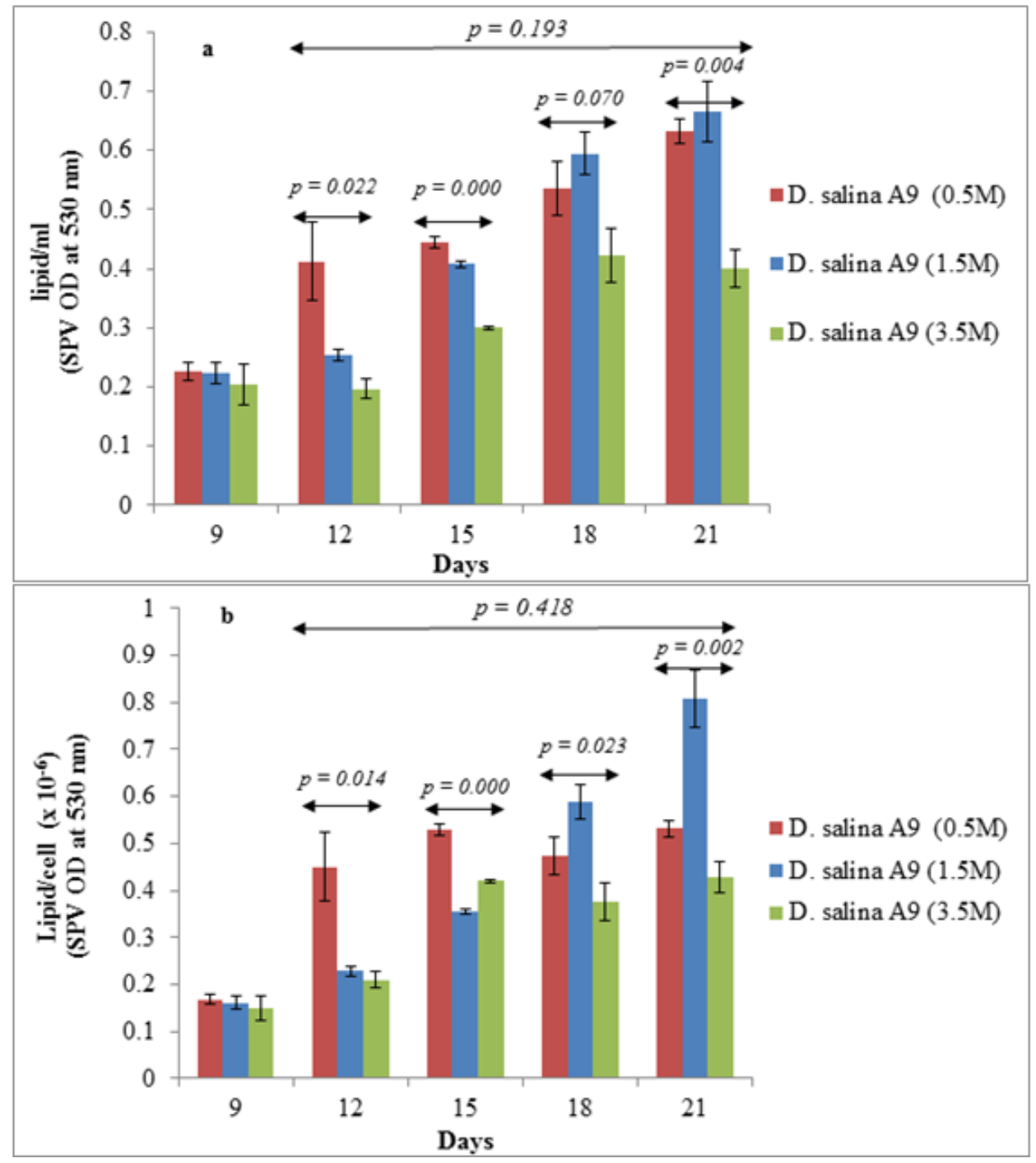

Figure 5. Lipid accumulation of D. salina A9, lipid per volume (a) and lipid per cell (b) under the different stress 


\section{Conclusion}

Dunaliella is unicellular green microalga, expecially Dunaliella salina can accumulate a larger amount of carotenoid under adverse conditions such as high irradiance, salinity, nutrient starvation. Dunaliella salina A9 isolated from the saltern, Khanh Hoa province, Viet Nam, used to investigate the growth, capacity of carotenoid and lipid accumulation under the osmotic stress and nutrient starvation. The results demonstrated that decrease in the growth rate, chlorophyll content and increase in carotenoid and lipid accumulation as stressed cells. The lower growth obtained with the salinity stress, while chlorophyll content was not significant difference after 3 days stress. However carotenoid and lipid accumulation of Dunaliella salina A9 were the highest with the hypo-osmotic stress $(0.5 \mathrm{M})$ and nutrient starvation. Previous studies demonstrated the antioxidant [27,35,37,40], antimicrobial [12,23] and anticancer [18] properties of the extract from Dunaliella salina under the stress conditions. Dunaliella salina A9 can apply to functional food and biofuel in Viet Nam, because of capacity of higher carotenoid and lipid accumulation under stress conditions. We will continue to study capacity of antioxidant, antibiotic and anticancer from extract of Dunaliella salina A9 under the stress conditions.

\section{Conflict of Interests}

The author(s) declare(s) that there is no conflict of interest regarding the publication of this article.

\section{References}

[1] Al-Hasan, R.H., Ghannoum, M.A., Sallal, A-K., Abu-Elteen, K.H. and Radwan, S.S., "Correlative Changes of Growth, Pigmentation and Lipid Composition of Dunaliella salina in Response to Halostress", Journal of General Microbiology, 1987, 133. 2607-2616.

[2] Avron, M. and Ben-Amotz, A., Dunaliella: physiology, biochemistry, and biotechnology. CRC Press, Boca Raton, FL, 1992, 256 pp.

[3] Azachi, M., Sadka, A., Fisher, M., Goldshlag, P., Gokhman, I. and Zamir, A., "Salt induction of Fatty acid elongase and membrane lipid modifications in the extreme halotolerant alga Dunaliella salina", Plant physiology, 2002, 129(3). 1320-1329.

[4] Ben-Amotz, A. and Evron, M., "On the factors which determine massive $\beta$-carotene accumulation in the halotolerant alga Dunaliella bardawil", Plant Physiol., 1983, 72. 593-597.

[5] Ben-Amotz, A., "Effect of Irradiance and Nutrient Deficiency on the Chemical Composition of Dunaliella bardawil Ben-Amotz and Avron (Volvocales, Chlorophyta)", J. Plant Physiol., 1987, 131. 479-487.

[6] Ben-Amotz, A., Katz, A. and Avron, M., "Accumulation of $\beta$ carotene in halotolerant algae: purification and characterization of $\beta$-carotene rich globules from Dunaliella bardawil (Chlorophyceae)", Journal of Phycology, 1982, 18. 529-537.

[7] Ben-Amotz, A., Shaish, A., Carotene biosynthesis. In: Avron M, Ben-Amotz, A. (Eds.). Dunaliella: Physiology, Biochemistry and Biotechnology. CRC Press, Boca Raton, FL, 1992. 206-216.

[8] Ben-Amotz, A., Tornabene, T., and Thomas, W.H., "Chemical profile of selected species of microalgae with emphasis on lipids", J. Phycol., 1985, 21. 72-81.

[9] Benavente-Valdés, J.R., Aguilar, C., Contreras-Esquivel, J.C., Méndez-Zavala, A., Montañez, J., "Strategies to enhance the production of photosynthetic pigments and lipids in chlorophycae species", Biotechnology Reports, 2016, 10. 117-125.

[10] Berges, J.A., Charwbois, O.D., Mauzerall, D.C., Falkowski, P.G., "Differential effects of nitrogen limitation on photosynthetic efficiency of photosystems I and II in microalgae", Plant Physiol., 1996, 110(2). 689-696.

[11] Boussiba, S., Vonshak, A., "Astaxanthin accumulation in the green alga Haematococcus pluvialis", Plant Cell Physiol., 1991, 32. 1077-1082.

[12] Cakmak, Y.S., Kaya, M., Asan-Ozusaglam, M., "Biochemical composition and bioactivity screening of various extracts from Dunaliella salina, a green microalga", Excli. Journal, 2014, 13. 679-690.

[13] Chen, H. and Jiang, J-G., "Osmotic responses of Dunaliella to the changes of salinity", J. Cell. Physiol., 2009, 219. 251-258.

[14] Coesel, S.N., Baumgartner, A.C., Teles, L.M., Ramos, A.A., Henriques, N.M., Cancela, L. and Varela, J.C.S., "Nutrient limitation is the main regulatory factor for carotenoid accumulation and for Psy and Pds steady state transcript levels in Dunaliella salina (Chlorophyta) exposed to high light and salt stress", Mar. Biotechnol., 2008, 10. 602-611.

[15] El-Baky, H.H.A., Baz, F.K.E. and El-Baroty, G.S., "Production of lipids rich in omega 3 fatty acids from the halotolerant alga Dunaliella salina", Biotechnology, 2004, 3(1). 102-108.

[16] Fisher, M., Gokhman, I., Pick, U. and Zamir, A., "A structurally novel transferrin-like protein accumulates in the plasma membrane of the unicellular green alga Dunaliella salina grown in high salinities", J. Biol. Chem., 1997, 272. 1565-1570.

[17] Fraser, P.D., Bramley, P.M., "The biosynthesis and nutritional uses of carotenoids", Prog. Lipid Res., 2004, 43. 228-265.

[18] Jayappriyan, K.R., Rajkumar, R., Venkatakrishnan, V., Nagaraj, S. Rengasamy, R., "In vitro anticancer activity of natural -carotene from Dunaliella salina. EU5891199 in PC-3 cells", Biomedicine and Preventive Nutrition, 2013, 3. 99-105.

[19] Li, Y., Horsman, M., Wang, B., Wu, N., Lan, C.Q., "Effects of nitrogen sources on cell growth and lipid accumulation of green alga Neochloris oleoabundans", Appl. Microbiol. Biotechnol., 2008, 81. 629-636.

[20] Lichtenthaler, H.K., Wellburn, A.R., "Determination of total carotenoids and chlorophylls A and B of leaf in different solvents", Biol. Soc. Trans., 1985, 11. 591-592.

[21] Liu, Z.Y., Wang, G.C., Zhou, B.C., "Effect of iron on growth and lipid accumulation in Chlorella vulgaris", Bioresour. Technol., 2008, 99. 4717-4722.

[22] Mai T., Nguyen P., Vo T., Huynh H., Tran S., Nim T., Tran D., Nguyen H. and Bui P., "Accumulation of lipid in Dunaliella salina under Nutrient Starvation Condition", American Journal of Food and Nutrition, 2017, 5(2). 58-61.

[23] Mendiola, J.A., Santoyo, S., Cifuentes, A., Reglero, G., Ibanez, E., and Senorans, F.J., "Antimicrobial Activity of Sub- and Supercritical $\mathrm{CO}_{2}$ Extracts of the Green Alga Dunaliella salina", Journal of Food Protection, 2008, 71(10). 2138-2143.

[24] Mendoza, H., Martel, A., Jiménez del Río, M. and García Reina, G., "Oleic acid is the main fatty acid related with carotenogenesis in Dunaliella salina", J. Appl. Phycol., 1999, 11.15-19.

[25] Minhas, A.K., Hodgson, P., Barrow, C.J. and Adholeya, A.A., "Review on the Assessment of Stress Conditions for Simultaneous Production of Microalgal Lipids and Carotenoids", Frontiers in Microbiology, 2016, 7. 1-19.

[26] Mishra, S.K., Suh, W.I., Farooq, W., Moon, M., Shrivastav, A., Park, M.S., Yang, J.W., "Rapid quantification of microalgal lipids in aqueous medium by a simple colorimetric method", Bioresource Technology, 2014, 155. 330-333.

[27] Murthy, K.N.C., Vanitha, A., Rajesha, J., Swamy, M.M., Sowmya, P.R., Ravishankar, G.A., "In vivo antioxidant activity of carotenoids from Dunaliella salina - a green microalga", Life Sciences, 2005, 76. 1381-1390.

[28] Ördög, V., Stirk, W., Bálint, P., Staden, J., Lovász, C., “Changes in lipid, protein and pigment concentrations in nitrogen-stressed Chlorella minutissima cultures", J. Appl. Phycol., 2012, 24. 907-914.

[29] Oren, A., "A hundred years of Dunaliella research: 1905-2005", Saline Systems, 2005, 1:2.

[30] Phadwal, K., Singh, P.K., "Effect of nutrient depletion on $b$ carotene and glycerol accumulation in two strains of Dunaliella sp", Bioresource Technology, 2003, 90. 55-58. 
[31] Pick, U., "Dunaliella - A model extremophilic alga", Israel Journal of Plant Sciences, 1998, 46(2). 131-139.

[32] Prieto, A., Canavate, J.P., García-González, M., "Assessment of carotenoid production by Dunaliella salina in different culture systems and operation regimes", Journal of Biotechnology, 2011, 151: 180-185.

[33] Ramos, A.A., Polle, J., Tran, D., Cushman, J.C., Jin, E. and Varela, J.C., "The unicellular green alga Dunaliella salina Teod. as a model for abiotic stress tolerance: genetic advances and future perspectives", Algae, 2011, 26(1). 3-20.

[34] Rao, A.R., Dayananda, C., Sarada, R., Shamala, T.R., Ravishankar, G.A., "Effect of salinity on growth of green alga Botryococcus braunii and its constituents", Bioresour. Technol., 2007, 98. 560-564.

[35] Safafar, H., Wagenen, J.V., Moller, P. and Jacobsen, C., "Carotenoids, Phenolic Compounds and Tocopherols Contribute to the Antioxidative Properties of Some Microalgae Species Grown on Industrial Wastewater", Mar. Drugs, 2015, 13. 7339-7356.
[36] Shaish, A., Ben-Amotz, A., Avron, M., "Biosynthesis of -carotene in Dunaliella", Methods Enzymol., 1992, 213. 439-444.

[37] Singh, P., Manoj, B. and Reddy, S.M., "Antioxidant and cytotoxic activity of carotenes produced by Dunaliella salina under stress", Pharmaceutical Biology, 2016, 54(10). 2269-2275.

[38] Tran, D., Mai, T., Vo T., Ward, A., Nguyen, H., Hoang, X., "Lipid Signal Can Be An Additional Marker For The Detection Of Dunaliella Salina", Wulfenia journal, 2014b, 21(12). 216-233.

[39] Tran, D., Doan, N., Louime, C., Giordano, M., Portilla, S., "Growth, antioxidant capacity and total carotene of Dunaliella salina DCCBC15 in a low cost enriched natural seawater medium", World Journal of Microbiology and Biotechnology, 2014a, 30(1). 317-322.

[40] Vo, T., Tran, D., "Carotene and Antioidant Capacity of Dunaliella Salina Strains", Journal of Nutrition and Health, 2014, 2(2). 21-23

[41] Yao, S., Lu, J., Sárossy, Z., Baggesen, C., Brandt, A. and An, Y. "Neutral lipid production in Dunaliella salina during osmotic stress and adaptation", J. Appl. Phycol., 2016, 28(4). 2167-2175. 